CASSOWARY volume 3 (2): 141 - 152

ISSN : 2614-8900

E-ISSN : 2622-6545

Program Pascasarjana Universitas Papua, https://pasca.unipa.ac.id/

\title{
Analisis Perubahan Tutupan Lahan di Kabupaten Manokwari Selatan
}

\author{
(Analysis of Changes in Land Cover in South Manokwari District)
}

Silvy E. Kesaulija ${ }^{*}$, Soetjipto Moeljono ${ }^{1}$, Agustinus Murdjoko

${ }^{1}$ Program Studi Magister Kehutanan, Program Pascasarjana Universitas Papua Jalan Gunung Salju Amban, Manokwari, 98314, Indonesia

*Email: s_moeljono@yahoo.com

\begin{abstract}
This study aims to determine the extent of land cover changes in South Manokwari Regency from 2009 to 2018, including what changes have occurred, where they have occurred, how much change has occurred and the factors causing forest area changes in South Manokwari Regency. The method used in this research was the overlay technique with the supervised classification method. Data collection and analysis were carried out spatially using ArcGIS 10.4 software. The research variables consisted of forest area and land cover in hectares, changes in land cover (deforestation and degradation) in hectares and factors that influenced changes in land cover in South Manokwari Regency. The analysis of land cover based on area functions, permits and district boundaries, found that there had been degradation and eforestation in South Manokwari Regency. The area of forest degradation is $8,870.15 \mathrm{Ha}$ that occurs inside the Production Forest in the IUPHHK concession area in Dataran Isim District. Meanwhile, the deforestation of 1,357.75 hectares occurred in other use areas. Other factors that influence land cover change were accessibility factors, government policies and topographical factors.
\end{abstract}

Keywords: land cover change, deforestation, degradation, South Manokwari Regency

ABSTRAK: Penelitian ini bertujuan untuk mengetahui luas perubahan tutupan lahan di Kabupaten Manokwari Selatan dari Tahun 2009 hingga tahun 2018, meliputi perubahan apa saja yang terjadi, dimana terjadinya, seberapa besar perubahan yang terjadi dan faktor penyebab terjadinya perubahan kawasan hutan di Kabupaten Manokwari Selatan. Metode yang digunakan dalam penelitian ini adalah dengan teknik overlay dengan metode klasifikasi terbimbing. Pengumpulan dan analisis data dilakukan secara spasial menggunakan perangkat lunak ArcGIS 10.4. Variabel penelitian terdiri dari luas kawasan hutan dan tutupan lahan dalam satuan hektar, perubahan tutupan lahan (deforestasi dan degradasi) dalam satuan hektar dan faktor-faktor yang mempengaruhi perubahan tutupan lahan di Kabupaten Manokwari Selatan. Berdasarkan hasil analisis tutupan lahan berdasarkan fungsi kawasan, perijinan dan batas distrik, ditemukan bahwa telah terjadi degradasi dan deforestasi di Kabupaten Manokwari Selatan. Luas degradasi hutan sebesar 8.870,15 Ha yang terjadi di dalam Hutan produksi pada areal konsesi IUPHHK di Distrik Dataran Isim. Sedangkan deforestasi hutan sebesar 1.357,75 Ha terjadi pada Areal Penggunaan Lain. Faktor lain yang mempengaruhi perubahan tutupan lahan adalah faktor aksesibilitas, kebijakan pemerintah dan faktor topografi. 
Kata kunci: Perubahan tutupan lahan, deforestasi, degradasi, Kabupaten Manokwari Selatan.

\section{PENDAHULUAN}

Perubahan fungsi hutan menjadi non hutan mengakibatkan degradasi dan deforestasi meningkat setiap tahun, sementara luas wilayah konstan, tidak bertambah dan terbatas dimana berbanding terbalik dengan jumlah penduduk yang semakin meningkat. Hal ini secara otomatis mempengaruhi tingkat kebutuhan lahan bagi masyarakat semakin meningkat untuk pemenuhan ekonomi penduduk.

Pertumbuhan penduduk dan peningkatan aktivitas ekonomi berimplikasi pada kebutuhan akan ruang, sedangkan ruang sifatnya tetap dalam arti luas tidak bertambah, namun dari sisi komposisi baik fisik, ekonomi dan sosial akan selalu berubah seiring perubahan pemanfaatan ruang. Pembangunan yang pesat telah menyebabkan perubahan pola penggunaan lahan, dimana ruang terbangun semakin mendominasi dan mendesak ruang-ruang alami untuk berubah fungsi. Fenomena tersebut kebanyakan terjadi diperkotaan dimana perubahan penggunaan lahan berlangsung secara dinamis (Pribadi, 2006).

Hubungan antara penataan ruang dengan penataan kawasan hutan dapat dilihat dari fungsi kawasan hutan. Lahan sebagai tempat dasar dari pada ruang menjadi salah satu faktor kunci untuk mengendalikan aktivitas di dalam ruang (Pribadi, 2006).

Keberadaan kawasan hutan dalam suatu wilayah merupakan bagian dari ruang wilayah provinsi maupun kabupaten/kota yang bersangkutan sehingga kebijakan penataan ruang wilayah provinsi dan kabupaten/kota akan memberikan implikasi luas terhadap keberadaan kawasan hutan tersebut.
Penutupan lahan merupakan salah satu data dan informasi strategis Kementerian Lingkungan Hidup dan Kehutanan yang selalu mengalami perubahan cepat dan dinamis. Perubahan dapat disebabkan oleh beberapa faktor, antara lain konversi lahan, pembukaan lahan perkebunan, pertambahan penduduk, pertumbuhan ekonomi dan perubahan fungsi kawasan hutan menjadi areal untuk penggunaan lain.

Saat ini hutan Papua terancam oleh deforestasi dan degradasi dengan adanya ekspor kayu log. Meski ada aturan di tingkat lokal maupun nasional tentang larangan kayu log keluar dari Papua. Penyusutan hutan di Papua diperkirakan sebesar 600 ribu $\mathrm{m} 3$ per bulan dan diduga terjadi laju deforestasi yang mencapai 2,8 juta ha pertahun.

Kabupaten Manokwari Selatan merupakan salah satu kabupaten pemekaran dari Provinsi Papua Barat yang terbentuk sejak tahun 2012 melalui Undang-undang Nomor 23 Tahun 2012 tentang Pembentukan Kabupaten Manokwari Selatan di Provinsi Papua Barat. Sejak terbentuknya kabupaten Manokwari Selatan tentunya membutuhkan ruang untuk pembangunan, sedangkan hampir $80 \%$ wilayah Kabupaten Manokwari Selatan merupakan kawasan hutan.

Tulisan ini bertujuan untuk menganalisis perubahan tutupan lahan di Kabupaten Manokwari Selatan dari Tahun 2009 hingga tahun 2018 dengan memanfaatkan SIG.

\section{METODE PENELITIAN}

Penelitian dilaksanakan di Dinas Kehutanan Provinsi Papua Barat Bidang Tata Hutan dan Pemanfaatan Kawasan untuk interpretasi Citra dengan cuplikan 
data di Kabupaten manokwari Selatan, data pengamatan lapangan dilakukan secara purposive di Kabupaten Manokwari Selatan pada beberapa titik sesuai dengan penggunaan lahan. Penelitian dilaksanakan dari bulan Maret - Juli 2020.

Alat yang digunakan yaitu GPS Mon-tana 680, kamera foto, aplikasi Avenza Map. Software yang digunakan untuk analisis citra dan tutupan lahan yaitu ArcGIS 10.4. Bahan yang digunakan adalah Peta tutupan lahan tahun 2009, 2012, 2015 dan 2018, data citra satelit landset 7 TM dan Landsat 8 Operational Land Imager (OLI), Peta kawasan hutan Provinsi Papua Barat (Lampiran SK. 783/Menhut-II/2014), peta administrasi kabupaten Manokwari Selatan dan data jumlah penduduk Kabupaten Manokwari Selatan.

\section{Variabel pengamatan}

Variabel yang diukur dalam penelitian ini terdiri dari luas kawasan hutan dan tutupan lahan dalam satuan hektar (ha), perubahan tutupan lahan (deforestasi dan degradasi hutan) dalam satuan hektar (ha) serta faktor-faktor yang mempengaruhi perubahan tutupan lahan di Kabupaten Manokwari Selatan.

\section{Pengumpulan data}

Tahapan Persiapan

Tahap persiapan merupakan rangkaian kegiatan sebelum memulai tahapan pengumpulan dan pengolahan data. Dalam tahap persiapan ini meliputi pengumpulan data dan informasi sekunder terkait peta kawasan hutan Provinsi Papua Barat, peta administrasi Kabupaten Manokwari Selatan, data statistik Kabupaten Manokwari Selatan dan penetapan jadwal serta lokasi pengambilan data lapangan.

\section{Pengumpulan data}

Data primer merupakan data hasil pengecekan langsung ke lapangan, titik pengamatan ditentukan dengan metode purposive sampling menggunakan GPS dan aplikasi Avenzamap pada smartphone. Sedangkan untuk data sekunder berupa peta tutupan lahan tahun 2009, 2012, 2015 dan 2018, peta administrasi, peta pola ruang RTRW.

Data sekunder yang digunakan untuk pendukung fakta hasil analisis. Data-data tersebut berupa data jumlah penduduk Kabupaten Manokwari Selatan, Jumlah Kampung, Data RTRW Kabupaten Manokwari Selatan, dan data pendukung lainnya yang relevan dengan penelitian ini.

\section{Pengolahan dan Analisis Data}

Perubahan tutupan lahan dianalisis menggunakan software ArcGIS 10.4. Metode pengklasifikasian yang digunakan adalah metode klasifikasi terbimbing (supervise classification). Analisis data yang dilakukan meliputi analisis spasial perubahan kawasan hutan dan tutupan lahan serta analisis faktor-faktor yang mempengaruhi perubahan tutupan lahan. Hasil analisis selanjutnya ditampilkan dalam bentuk tabel, grafik dan peta.

Tahap penghitungan data perubahan tutupan lahan adalah sebagai berikut:

1. Overlay data digital penutupan lahan hasil penafsiran interpretasi citra untuk tahun 2009, 2012, 2015 dan 2018.

2. Overlay data digital penutupan lahan dengan peta digital kawasan hutan Kabupaten Manokwari Selatan berdasarkan SK. Menhut No. 783/Menhut-II/2014.

3. Menghitung luas perubahan tutupan lahan

Perhitungan perubahan tutupan lahan hutan adalah sebagai berikut:

$$
\mathrm{PTH}=\mathrm{A}_{1}-\mathrm{A}_{0}
$$


$\begin{aligned} \mathrm{A}_{0}: & \text { Luas hutan pada } \\ \text { pengamatan awal (ha) } & \text { waktu } \\ \mathrm{A}_{1}: & \text { Luas hutan pada } \\ & \text { pengamatan akhir (ha) }\end{aligned}$

\section{HASIL DAN PEMBAHASAN}

\section{Luas Kawasan Hutan dan Perubahan Tutupan Lahan Kabupaten Manok- wari Selatan}

Kawasan hutan adalah wilayah tertentu yang ditunjuk dan atau ditetapkan oleh pemerintah untuk dipertahankan keberadaannya sebagai hutan tetap. Penunjukan kawasan hutan di Provinsi Papua Barat telah mengalami perubahan yaitu yang pertama berdasarkan Keputusan Menteri Kehutanan dan Perkebunan Nomor: 891/KptsII/1999 tentang Penunjukan Kawasan Hutan di Wilayah Provinsi Daerah Tingkat I Irian Jaya Seluas 42.224.840 ha, selanjutnya ditetapkan dengan Surat Keputusan Menteri Kehutanan Nomor: SK.783/Menhut-II/2014 tentang Kawasan Hutan dan Konservasi Perairan Papua Barat. Berdasarkan fungsinya hutan terdiri dari Hutan Konservasi (Cagar Alam, Suaka Marga Satwa, Taman Nasional, Taman Wisata Alam, Taman Hutan Raya), Hutan Lindung dan Hutan Produksi (Hutan Produksi Tetap, Hutan Produksi Terbatas dan Hutan Produksi yang dapat dikonversi). Untuk analisis data menggunakan penunjukan kawasan berdasarkan SK.783/Menhut-II/2014 tentang Kawasan Hutan dan Konservasi Perairan Papua Barat.

Kabupaten Manokwari Selatan merupakan salah satu kabupaten hasil pemekaran dari Kabupaten Manokwari di Provinsi Papua Barat yang dibentuk berdasarkan UU No. 23 Tahun 2012. Secara geografis Kabupaten Manokwari Selatan terletak pada $0,15^{\circ}-3,025^{\circ} \mathrm{LS}$ dan $132^{\circ}-134^{\circ}$ BT dengan luas wilayah 2.789,12 $\mathrm{Km}^{2}$ meliputi daratan dan lautan.
Berdasarkan penunjukan kawasan hutan Provinsi Papua Barat, maka luas kawasan hutan untuk Kabupaten Manokwari Selatan seperti pada Gambar 1. Berdasarkan Gambar 1, Kabupaten Manokwari Selatan memiliki luas $\mathrm{Hu}-$ tan Lindung yang tertinggi yaitu seluas 72.427 ha yang disusul dengan hutan produksi terbatas seluas 57.152 ha.

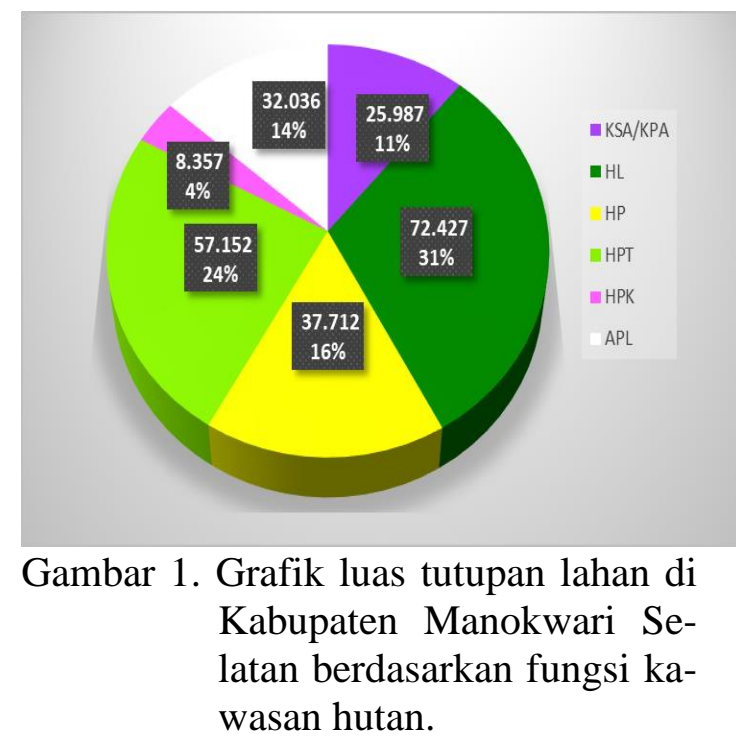

Kabupaten Manokwari Selatan pada awalnya merupakan kawasan yang didominasi oleh kawasan hutan primer, namun seiring dengan perkembangan pembangunan maka pemanfaatan hutan tidak dapat terelakkan. Dimana sebagian besar kawasan pesisir merupakan kawasan pertanian lahan kering (perkebunan) dan beberapa areal merupakan lahan terbuka non produktif.

Berdasarkan hasil analisis peta penutupan lahan dari Kementerian Lingkungan Hidup dan Kehutanan terdapat 19 kelas tutupan lahan di Kabupaten Manokwari Selatan. Dari hasil perhitungan maka luas perubahan tutupan lahan yang terjadi dapat dilihat padaTabel 1. 
Tabel 1. Luas tutupan lahan Kabupaten Manokwari Selatan tahun 2009, 2012, 2015 dan 2018

\begin{tabular}{|c|c|c|c|c|c|c|c|c|c|}
\hline \multirow[b]{2}{*}{ NO. } & \multirow{2}{*}{$\begin{array}{l}\text { TUTUPAN } \\
\text { LAHAN }\end{array}$} & \multicolumn{2}{|c|}{ Tahun 2009} & \multicolumn{2}{|c|}{ Tahun 2012} & \multicolumn{2}{|c|}{ Tahun 2015} & \multicolumn{2}{|c|}{ Tahun 2018} \\
\hline & & $\begin{array}{l}\text { Luas } \\
\text { (Ha) }\end{array}$ & $\%$ & $\begin{array}{l}\text { Luas } \\
\text { (Ha) }\end{array}$ & $\%$ & $\begin{array}{l}\text { Luas } \\
\text { (Ha) }\end{array}$ & $\%$ & $\begin{array}{r}\text { Luas } \\
\text { (Ha) }\end{array}$ & $\%$ \\
\hline 1 & $\begin{array}{l}\text { Hutan lahan } \\
\text { kering primer }\end{array}$ & 141.458 & 61 & 141.403 & 61 & 133.749 & 57 & 132.425 & 57 \\
\hline 2 & $\begin{array}{l}\text { Hutan lahan } \\
\text { kering } \\
\text { sekunder }\end{array}$ & 57.776 & 25 & 57.559 & 25 & 65.001 & 28 & 65.476 & 28 \\
\hline 3 & $\begin{array}{l}\text { Hutan } \\
\text { Mangrove } \\
\text { Primer }\end{array}$ & 713 & 0 & 713 & 0 & 713 & 0 & 574 & 0 \\
\hline 4 & $\begin{array}{l}\text { Hutan } \\
\text { mangrove } \\
\text { sekunder }\end{array}$ & 494 & 0 & 494 & 0 & 494 & 0 & 608 & 0 \\
\hline 5 & $\begin{array}{c}\text { Hutan Rawa } \\
\text { Primer }\end{array}$ & 567 & 0 & 567 & 0 & 567 & 0 & 567 & 0 \\
\hline 6 & $\begin{array}{l}\text { Hutan rawa } \\
\text { sekunder }\end{array}$ & 3.364 & 1 & 3.364 & 1 & 3.364 & 1 & 3.364 & 1 \\
\hline 7 & Belukar rawa & 153 & 0 & 153 & 0 & 153 & 0 & 193 & 0 \\
\hline 8 & Pemukiman & 2.042 & 1 & 2.050 & 1 & 2.052 & 1 & 2.590 & 1 \\
\hline 9 & Perkebunan & 1.809 & 1 & 1.809 & 1 & 1.809 & 1 & 1.834 & 1 \\
\hline 10 & $\begin{array}{l}\text { Pertanian } \\
\text { lahan kering }\end{array}$ & 1.289 & 1 & 1.289 & 1 & 1.289 & 1 & 775 & 0 \\
\hline 11 & $\begin{array}{l}\text { Pertanian } \\
\text { lahan Kering } \\
\text { bercampur } \\
\text { semak }\end{array}$ & 1.490 & 1 & 1.490 & 1 & 1.477 & 1 & 1.686 & 1 \\
\hline 12 & Rawa & 122 & 0 & 122 & 0 & 122 & 0 & 123 & 0 \\
\hline 13 & Savana & 6.309 & 3 & 6.309 & 3 & 6.309 & 3 & 5.483 & 2 \\
\hline 14 & Sawah & 1.070 & 0 & 1.070 & 0 & 1.070 & 0 & 613 & 0 \\
\hline 15 & $\begin{array}{l}\text { semak } \\
\text { belukar }\end{array}$ & 14.857 & 6 & 15.113 & 6 & 15.325 & 7 & 16.751 & 7 \\
\hline 16 & $\begin{array}{l}\text { Tanah } \\
\text { terbuka }\end{array}$ & 157 & 0 & 164 & 0 & 175 & 0 & 414 & 0 \\
\hline 17 & Pelabuhan & - & - & - & - & - & - & 8 & 0 \\
\hline 18 & Transmigrasi & - & - & - & - & - & - & 182 & 0 \\
\hline 19 & tubuh air & 2 & 0 & 2 & 0 & 2 & 0 & 2 & 0 \\
\hline & Total & 233.671 & 100 & 233.671 & 100 & 233.671 & 100 & 233.671 & 100 \\
\hline
\end{tabular}

Berdasarkan Tabel 2. Menun-jukkan bahwa tutupan lahan di Kabu-paten Manokwari Selatan didominasi oleh kawasan hutan baik hutan primer maupun hutan sekunder. Dimana dari tahun 2009 hingga 2018 terjadi penurunan luas tutupan hutan lahan kering primer seluas 9.033 ha. Sebaliknya hu- tan lahan kering sekunder dan semak belukar mengalami peningkatan pada tahun 2018 yaitu masing-masing sebesar 7.700 ha dan 1.894 ha. Peningkatan semak belukar ini merupakan dampak dari pembukaan areal pertanian untuk masyarakat. Sedangkan pengurangan luas savana diakibatkan oleh bertam- 
bahnya pemukiman sebagai dampak dari pemekaran kampung. Rata-rata penurunan tutupan lahan hutan untuk hutan lahan kering primer dari tahun 2009 hingga tahun 2018 sebesar 903,3 ha/tahun, sedangkan untuk hutan lahan kering sekunder mengalami peningkatan sebesar 770 ha/tahun.

\section{Penggunaan tutupan lahan di} Kabupaten Manokwari Selatan dari tahun 2009 sampai dengan tahun 2018

Penggunaan kawasan hutan menyebabkan terjadinya perubahan tutupan lahan. Perubahan tutupan lahan dapat berupa deforestasi dan degradasi.
Deforestasi adalah perubahan tutupan lahan dari hutan menjadi bukan hutan akibat alih fungsi hutan menjadi penggunaan lain seperti pemukiman, lahan pertanian, semak belukar, tanah terbuka dan lain-lain. Sedangkan degradasi hutan merupakan perubahan tutupan lahan dari hutan primer menjadi hutan sekunder.

\section{Deforestasi Berdasarkan Fungsi Kawasan}

Berdasarkan hasil perhitungan, luas deforestasi yang terjadi pada kawasan hutan maupun non hutan di Kabupaten Manokwari

Tabel 2. Luas perubahan tutupan lahan di Kabupaten Manokwari Selatan pada Tahun tahun 2009 dan tahun 2018

\begin{tabular}{|c|c|c|c|c|c|c|c|}
\hline \multirow[b]{2}{*}{ NO. } & \multirow[b]{2}{*}{ TUTUPAN LAHAN } & \multicolumn{2}{|c|}{ Tahun 2009} & \multicolumn{2}{|c|}{ Tahun 2018} & \multicolumn{2}{|c|}{ Perubahan } \\
\hline & & $\begin{array}{l}\text { Luas } \\
\text { (Ha) }\end{array}$ & $\%$ & $\begin{array}{l}\text { Luas } \\
\text { (Ha) }\end{array}$ & $\%$ & $\begin{array}{l}\text { Luas } \\
\text { (Ha) }\end{array}$ & $\%$ \\
\hline 1 & Hutan lahan kering primer & 141.458 & 61 & 132.425 & 57 & -9.033 & $-3,87$ \\
\hline 2 & Hutan lahan kering sekunder & 57.776 & 25 & 65.476 & 28 & 7.700 & 3,30 \\
\hline 3 & Hutan Mangrove Primer & 713 & 0 & 574 & 0 & -139 & $-0,06$ \\
\hline 4 & Hutan mangrove sekunder & 494 & 0 & 608 & 0 & 114 & 0,05 \\
\hline 5 & Hutan Rawa Primer & 567 & 0 & 567 & 0 & 0 & 0,00 \\
\hline 6 & Hutan rawa sekunder & 3.364 & 1 & 3.364 & 1 & 0 & 0,00 \\
\hline 7 & Belukar rawa & 153 & 0 & 193 & 0 & 40 & 0,02 \\
\hline 8 & Pemukiman & 2.042 & 1 & 2.590 & 1 & 549 & 0,23 \\
\hline 9 & Perkebunan & 1.809 & 1 & 1.834 & 1 & 25 & 0,01 \\
\hline 10 & Pertanian lahan kering & 1.289 & 1 & 775 & 0 & -514 & $-0,22$ \\
\hline 11 & $\begin{array}{l}\text { Pertanian lahan Kering } \\
\text { bercampur semak }\end{array}$ & 1.490 & 1 & 1.686 & 1 & 197 & 0,08 \\
\hline 12 & Rawa & 122 & 0 & 123 & 0 & 1 & 0,00 \\
\hline 13 & savana/padang rumput & 6.309 & 3 & 5.483 & 2 & -825 & $-0,35$ \\
\hline 14 & Sawah & 1.070 & 0 & 613 & 0 & -457 & $-0,20$ \\
\hline 15 & semak belukar & 14.857 & 6 & 16.751 & 7 & 1.894 & 0,81 \\
\hline 16 & Tanah terbuka & 157 & 0 & 414 & 0 & 257 & 0,11 \\
\hline 17 & Bandara/pelabuhan & - & - & 8 & 0 & 8 & 0,00 \\
\hline 18 & Transmigrasi & - & - & 182 & 0 & 182 & 0,08 \\
\hline 19 & tubuh air & 2 & 0 & 2 & 0 & 0 & 0,00 \\
\hline & Total & 233.671 & 100 & 233.671 & 100 & & \\
\hline
\end{tabular}


Selatan dari tahun 2009 hingga 2018 menunjukkan bahwa deforestasi tertinggi pada fungsi kawasan Areal Penggunaan Lain (APL) seluas 650,44 ha atau $47,91 \%$. Secara penampakan dari peta citra, kawasan yang telah ditetapkan sebagai APL ini kondisinya dilapangan masih berupa hutan yang mengalami perubahan menjadi bukan hutan dari tahun 2009 hingga tahun 2018.

Secara grafis persentase deforetasi kawasan hutan di Kabupaten Manokwari Selatan dari tahun 2009 sampai dengan tahun 2018 berdasarkan fungsi kawasan hutan dapat dilihat pada Gambar 2.

Hasil perhitungan luas deforestasi yang terjadi di Kabupaten Manokwari Selatan tahun 2018 dibandingkan dengan tahun 2009 menunjukkan bahwa deforestasi tertinggi di Distrik Oransbari seluas 588,51 ha. Hal ini disebabkan karena topografi dari Distrik Oransbari lebih banyak daerah datar dibandingkan distrik-distrik lainnya sehingga pembukaan areal untuk kebun masyarakat lebih dominan di Distrik Oransbari, sehingga terjadi perubahan yang besar yaitu menjadi semak dan lahan terbuka.

\section{Luas Degradasi Berdasarkan Fungsi Kawasan}

Secara grafis persentase degradasi kawasan hutan di Kabupaten Manokwari Selatan dari tahun 2009 sampai dengan tahun 2018 berdasarkan fungsi kawasan hutan dapat dilihat pada Gambar 3.

Berdasarkan Gambar 3, luas degradasi pada kawasan hutan di Kabupaten Manokwari Selatan tahun 2018 dibandingkan dengan tahun 2009 menunjukkan bahwa degradasi terbesar terjadi di Hutan Produksi (HP) dengan penggunaan tutupan lahan dari Hutan Lahan Kering Primer menjadi Hutan Lahan Kering Sekunder dengan luas 4.607,44 ha, selanjutnya disusul dengan perubahan pada Hutan Produksi Terbatas yaitu seluas 3.129,49 ha, yaitu perubahan dari Hutan Lahan Kering Primer menjadi Hutan Lahan Kering Sekunder.

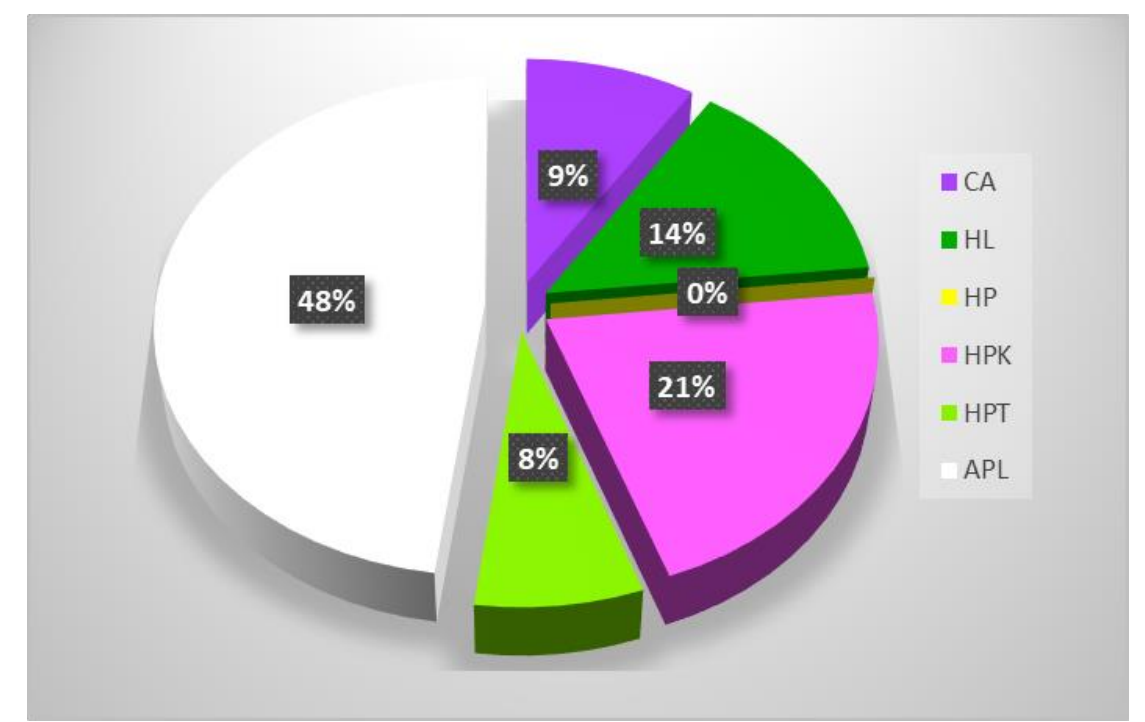

Gambar 2. Grafik deforestasi kawasan hutan di Kabupaten Manokwari Selatan tahun 2009 sampai dengan tahun 2018 


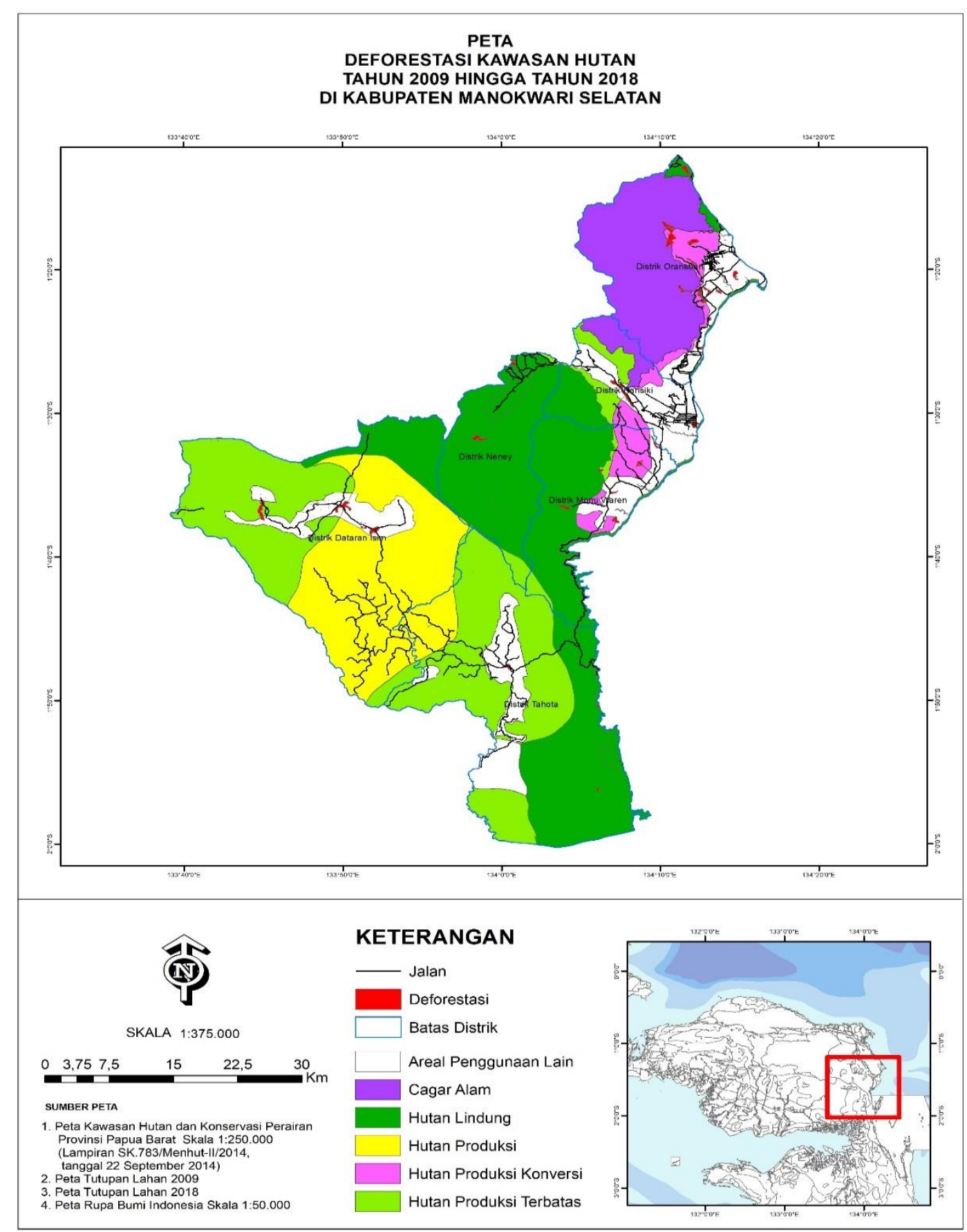

Gambar 3. Peta Deforestasi Kawasan Hutan Kabupaten Manokwari Selatan tahun 2009 dan tahun 2018

Sedangkan berdasarkan hasil perhitungan kawasan hutan Cagar Alam memiliki tingkat degradasi terkecil yaitu 4,30 ha atau $0,05 \%$ dari total luas kawasan hutan yang terdegradasi.

Hutan Produksi memiliki tingkat degradasi tertinggi karena hutan produksi merupakan kawasan hutan yang mempunyai fungsi pokok mem-produksi hasil hutan, dan pemanfaatan hutan produksi dapat berupa pemanfaatan hasil hutan kayu dan bukan kayu yang dilaksanakan melalui pemberian izin usaha pemanfaatan kawasan maupun izin pemungutan hasil hutan kayu. Degradasi terbesar ini terjadi pada areal 
konsesi IUPHHK-HA PT. Megapura Mamberamo Bangun, dimana luas yang terdegradasi seluas $6.110,11$ ha, sedangkan luas deforestasi pada areal konsesi ini hanya seluas kurang lebih 229,59 ha.

Luas Degradasi berdasarkan hasil perhitungan untuk tahun 2018 dibandingkan dengan tahun 2009 menunjukkan degradasi tertinggi terdapat di Distrik Dataran Isim yaitu seluas 7.725,60 Ha. Perubahan dari hutan lahan kering primer menjadi hutan lahan kering sekunder umumnya terdapat di areal konsesi IUPHHK PT. Megapura Mamberamo Bangun.

Dalam pembahasan penelitian ini, degradasi yang terjadi di areal Konsesi PT. Megapura Mamberamo Bangun dapat dikesampingkan karena merupakan perusahaan yang bergerak pada bidang kehutanan yang telah memiliki izin dari Menteri Kehutanan untuk memanfaatkan dan mengelola kawasan hutan yang diberikan sesuai dengan peraturan yang berlaku.

Selain deforestasi dan degradasi, faktor lainnya yang jadi penyebab perubahan tutupan lahan antara lain kebijakan pemerintah daerah dan pertumbuhan jumlah penduduk. Kebijakan pemerintah daerah ini terkait dengan pemekaran kabupaten maupun pemekaran kampung, yang disesuaikan dengan pola Tata Ruang Wilayah Kabu- paten. Kebijakan ini di ambil dalam rangka peningkatan pembangunan di Kabupaten Manokwari Selatan. Beberapa kebijakan penggunaan kawasan hutan yang mengakibat perubahan tutupan lahan antara lain pembukaan kawasan hutan untuk lokasi perkantoran namun pada akhirnya menjadi Rindam Kodam Papua Barat. Demikian pula pemberian izin untuk pengolahan pasir kuarsa sebagai bahan baku pabrik SDIC, dimana status fungsi kawasan hutan lindung diubah statusnya menjadi kawasan hutan produksi. Untuk tahun 2020 telah dikeluarkan juga izin untuk pembangunan Sekolah.

Kabupaten Manokwari Selatan merupakan kabupaten pemekaran dari Kabupaten Manokwari dengan partumbuhan penduduk yang cukup pesat. Hal ini dipengaruhi karena Kabupaten Manokwari Selatan merupakan kabupaten penghubung antar Kabupaten Manokwari dengan Kabupaten Teluk Bintuni dan Kabupaten Teluk Wondama. Penduduk Kabupaten Manokwari Selatan berdasarkan hasil proyeksi penduduk tahun 2018 sebanyak 23.617 jiwa yang terdiri atas 12.279 jiwa penduduk laki-laki dan 11.338 jiwa penduduk perempuan. Di mana kenaikan jumlah penduduk dari tahun 2012 hingga tahun 2018 sebesar 4.927 jiwa.

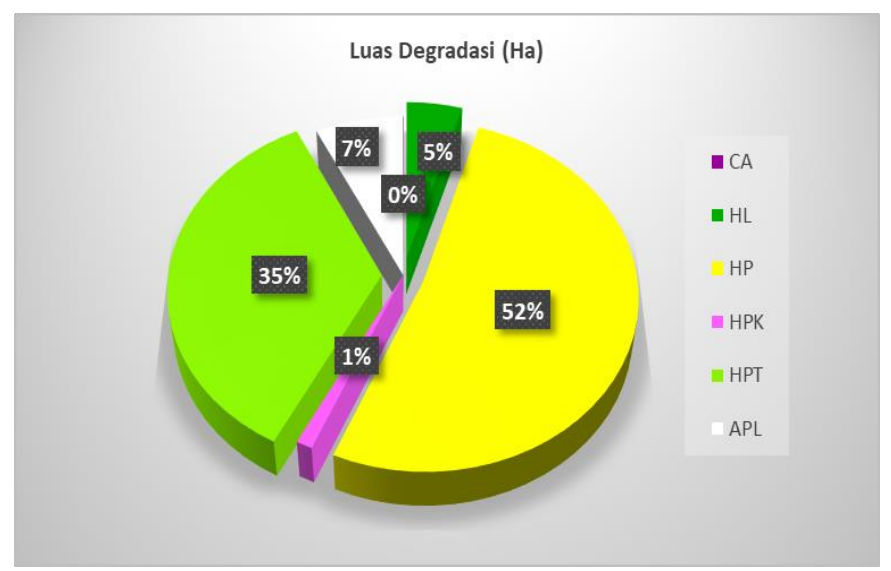

Gambar 4. Grafik degradasi kawasan hutan di Kabupaten Manokwari Selatan tahun 2009 sampai dengan tahun 2018 


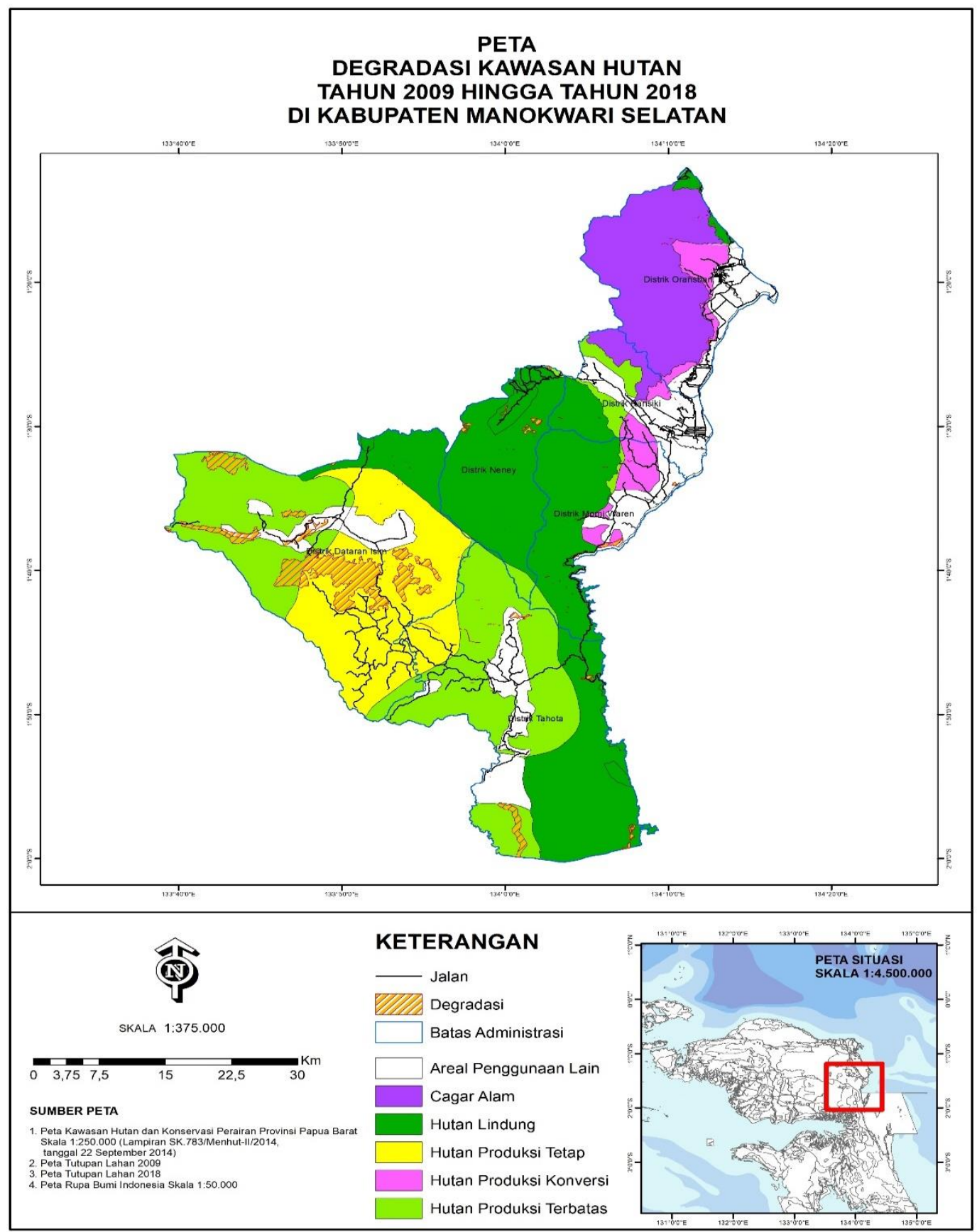

Gambar 5. Peta Degradasi Kawasan Hutan Kabupaten Manokwari Selatan tahun 2009 dan tahun 2018

Penambahan ini akan terus meningkat sedangkan jumlah ruang yang tersedia untuk kawasan budidaya tidak mengalami perubahan (Sumber : Manokwari Selatan dalam angka tahun 2019).

Dalam perencanaan tata ruang salah satu hal yang mendasar adalah topografi, dimana kondisi ketinggian topografi merupakan batas aman suatu kawasan untuk berbagai peruntukan, mulai dari pemukiman, pertanian hingga akses jalan penghubung antar kabupaten. Kabupaten Manokwari Selatan memiliki topografi yang bervariasi mulai dari pesisir pantai hingga pengu- 
nungan dengan perbukitan yang hampir mengelilingi sebagian besar wilayah kabupaten.

Informasi perubahan tutupan lahan yang disebabkan oleh degradasi dan deforestasi dapat dipakai dalam penyusunan perencanaan, pengelolaan sumber daya hutan dan acuan dalam melaksanakan perencanaan penggunaan ruang. Hasil perhitungan perubahan tutupan lahan tahun 2018 merupakan kondisi tutupan kawasan hutan terakhir dan dapat digunakan menjadi acuan dalam penyusunan perencanaan penggunaan ruang.

\section{KESIMPULAN}

1. Secara umum dari tahun 2009 hingga tahun 2018 di Kabupaten Manokwari Selatan telah mengalami perubahan tutupan lahan. Dimana dari tahun 2009 hingga 2018 terjadi penurunan luas tutupan hutan lahan kering primer seluas 9.033 ha. Sebaliknya hutan lahan kering sekunder dan semak belukar mengalami peningkatan pada tahun 2018 yaitu masingmasing sebesar 7.700 ha dan 1.894 ha.

2. Penggunaan tutupan lahan menyebabkan terjadinya perubahan tutupan lahan. Penyebab perubahan tutupan lahan adalah deforestasi dan degradasi. Luas kawasan hutan dan areal penggunaan lain yang terdeforestasi seluas $1.357,75$ ha dengan persentase tertinggi pada kawasan areal penggunaan lain (APL), sedangkan luas tutupan lahan yang terdegradasi seluas $8.870,15$ ha pada kawasan hutan produksi.

3. Selain deforestasi dan degradasi, faktor lainnya yang jadi penyebab perubahan tutupan lahan antara lain kebijakan pemerintah daerah dan pertumbuhan jumlah penduduk. Kebijakan pemerintah daerah ini terkait dengan pemekaran kabupaten mau- pun pemekaran kampung, yang disesuaikan dengan pola Tata Ruang Wilayah Kabupaten.

\section{DAFTAR PUSTAKA}

Balai Pemantapan Kawasan Hutan Wilayah XVII Manokwari. 2017. Penutupan Lahan Provinsi Papua Barat Tahun 2016. BPKH Wilayah XVII. Manokwari. $77 \mathrm{hlm}$.

Badan Pusat Statistik. 2019. Manokwari Selatan dalam Angka. Manokwari.

Direktorat Inventarissi dan Pemantauan Sumber Daya Hutan. 2012: Penghitungan Deforestasi Indonesia Periode 2009 - 2011. Kementerian Kehutanan. Jakarta. 37 hlm.

Direktorat Inventarissi dan Pemantauan Sumber Daya Hutan. 2012: Penghitungan Deforestasi Indonesia Periode 2012 - 2013. Kementerian Lingkungan Hidup dan Kehutanan. Jakarta. 131 hlm.

FWI/GFW. 2001. Keadaan Hutan Indonesia : Forest Watch Indonesia dan Washington DC, Global Forest Watch. Bogor. 102 hlm.

Forest Watch Indonesia. 2014. Potret Keadaan Hutan Indonesia Periode 2009 - 2013. Forest Watch Indonesia. Bogor. $129 \mathrm{hlm}$.

Jaya, I.N.S. 2014. Analisis Citra Digital. Perspektif Penginderaan Jauh Untuk Pengelolaan Sumber Daya Alam : IPB Press. Bogor. 372 hlm.

Kesaulija, F. F 2018. Pemodelan Spasial Dinamika Perubahan Tutupan Lahan di Provinsi Papua Barat (Studi Kasus Kabupaten Manokwari, Sorong, Sorong Selatan, Maybrat dan Kota Sorong). 
Universitas

Mulawarman.

Samarinda. $129 \mathrm{hlm}$.

Maryani R, S. Astana, 2016. Perubahan Tutupan Hutan di Kabupaten Paser, Kalimantan Timur : Penjelasan dari pendekatan kelembagaan. Jurnal Analisis Kebijakan Vol. 13 No. 3. Bogor : 1730184.

Pribadi, D. O, D. Shiddiq, M. Ermyanila. 2006. Model Perubahan Tutupan Lahan dan Faktor-faktor yang Mempengaruhinya. Jurnal Teknik Lingkungan. P3TL-BPPT. 7 (1) : $35-51$.

Purwandi, F.S.H,. P. Kardono, A. Kardini, N.S.Haryani, Rokhmatuloh. 2015. Aplikasi Penginderaan Jauh Sistem
Informasi Geografis Untuk Pengembangan Wilayah. Polimedia Publishing. Jakarta. 491 hlm.

Talakua, S.M. 2016.Degradasi Lahan : Metode Analisis dan Aplikasinya dalam Penggunaan Lahan. Plantaxia. Yogyakarta. $142 \mathrm{hlm}$.

Undang-undang RI Nomor 41 Tahun 1999 tentang Kehutanan.

Undang-undang RI Nomor 26 Tahun 2007 Tentang Penataan Ruang

Undang-undang RI Nomor 23 Tahun 2012 Tentang Pembentukan abupaten Manokwari Selatan. 